This is a post-print version of:

María-Ángeles Castillejo*, Sara Fondevilla-Aparicio, Carlos Fuentes-Almagro and Diego Rubiales

Quantitative Analysis of Target Peptides Related to Resistance Against

Ascochyta Blight (Peyronellaea pinodes) in Pea

Journal of Proteome Research 2020, 19, 1000-1012

The printed version can be visited at:

https://dx.doi.org/10.1021/acs.jproteome.9b00365 


\section{Quantitative analysis of target peptides related to resistance against Ascochyta blight (Peyronellaea pinodes) in pea}

María-Ángeles Castillejo $^{1 *}$, Sara Fondevilla-Aparicio ${ }^{1}$, Carlos Fuentes-Almagro ${ }^{2}$ and Diego Rubiales ${ }^{1}$

${ }^{1}$ Institute for Sustainable Agriculture, CSIC, Córdoba, Spain

${ }^{2}$ Proteomics Facility, SCAI, University of Córdoba, Córdoba, Spain

*Corresponding author: María-Ángeles Castillejo; E-mail: bb2casam@uco.es; Current address: Department of Biochemistry and Molecular Biology, University of Córdoba, Córdoba, Spain. 


\section{Highlight}

A proteomics strategy based on quantitative peptide estimation with Ascochyta blight as a model pathosystem was developed to identify potential protein markers associated to biological resistance in pea. 


\begin{abstract}
Peyronellaea pinodes causes Ascochyta blight, one of the major diseases of pea worldwide. Cultivated pea plants have a low resistance to this disease. Although Quantitative Traits Loci (QTL) involved in the resistance to Ascochyta blight have been identified, the specific genes associated to these QTL remain unknown, which makes marker-assisted selection difficult. Complex traits alter proteins and their abundance. Quantitative estimation of proteins in pea might therefore be useful to select potential markers for breeding. In this work, we developed a strategy using a combination of shotgun proteomics (viz., high performance liquid chromatography-mass spectrometry Data-Dependent Acquisition (DDA)) and Data-Independent Acquisition (DIA) analysis, to identify putative protein markers associated to resistance to Ascochyta blight, and explored its use for breeding selection. For this purpose, an initial list of target peptides based on proteins closely related to resistance to $P$. pinodes was compiled by using two genotypes with contrasting responses to the disease. Then, targeted data analysis (viz., shotgun proteomics-DIA) was used for constitutive quantification of the target peptides in a representative number of the Recombinant Inbred Line (RIL) population segregating for resistance as derived from a cross between the two genotypes. Finally, a peptide panel of potential markers for resistance to $P$. pinodes was built. The results thus obtained are discussed and compared with those of previous gene expression studies using the same parental pea genotypes responding to the pathogen. Also, a molecular defense mechanism against Ascochyta blight in pea is proposed. To the authors' knowledge, this is the first time a targeted proteomic approach based on data analysis has been used to identify peptides associated to resistance to this disease.
\end{abstract}

Keywords: peptide markers, resistance, targeted proteomic analysis, shotgun-DataDependent Acquisition (DDA), Data-Independent Acquisition (DIA), pea, Ascochyta blight. 


\section{INTRODUCTION}

Pisum sativum L. (dry pea) is a pulse crop of global economic importance. In fact, this is the most widely cultivated pulse crop in Europe and the second in the world (FAOSTAT 2014; http://faostat.fao.org/). Field pea production is currently affected by various abiotic and biotic stresses ${ }^{1}$. Specifically, Peyronellaea pinodes (formerly called Mycosphaerella pinodes, the teleomorph of Ascochyta pinodes) causes Aschochyta blight, which is the most serious foliar disease of pea cultivars worldwide. ${ }^{2}$ This fungus occurs widely in temperate regions, ${ }^{3,4}$ and, together with broomrape (Orobanche crenata Forsk), constitutes the greatest constraint on pea production in the Mediterranean basin., ${ }^{5,6}$ Because existing control practices for Ascochyta blight are largely uneconomical and inefficient, ${ }^{7}$ the use of resistant cultivars to fight the disease tends to be preferred. In any case, some pea cultivars (particularly Pisum wild species) are moderately resistant to Ascochyta blight. ${ }^{8-10}$ Thus, the $P$. sativum ssp. syriacum (P665) line has proved resistant to all tested isolates of $P$. pinodes. ${ }^{10}$ This genotype exhibits partial resistance in the form of limited colonization by the fungus and smaller lesions. ${ }^{11}$ In a previous study, the Recombinant Inbred Line (RIL) population obtained by crossing the partially resistant line P665 and the susceptible P. sativum ssp. sativum (cv. Messire) was used to develop a genetic map that allowed eleven QTL controlling resistance to $P$. pinodes to be identified. ${ }^{12}$ Also, using the SuperSAGE technique in combination with a Medicago truncatula microarray ${ }^{13,14}$ allowed genes differentially expressed in the response of the two genotypes to $P$. pinodes to be identified. Consistent with the results provided by $\mathrm{P} 665$, other studies on $P$. pinodes have revealed that biological resistance in pea is a polygenic trait involving various QTLs with minor effects. ${ }^{15-22}$ Some such QTLs are also present in other genetics backgrounds; ${ }^{23}$ also, their resistance mechanisms have been deciphered. ${ }^{12}$ However, the resistance genes associated to most of these QTLs remain unknown. Efficient Marker-Assisted Selection (MAS) entails the precise identification of the resistance genes most closely related to the QTL in question.

Marker-assisted plant breeding frequently requires predicting phenotypes at the genomic level. However, major agronomic traits are frequently associated to complex molecular mechanisms comprising several stages of regulation that involve genes expression, post-translational modifications and protein interactions. Because transcription and translation are intermediate steps between the genome and the 
phenotype, transcriptomic analyses are broadly used to predict phenotypes with a view to mapping populations. ${ }^{24}$

Quantitative protein estimation has emerged as a useful method to find markers for complex traits such as those involving protein modifications and changes in their abundance. Using in silico Mass Spectrometry (MS) assay libraries jointly with extraction of targeted peptide signals has proved effective for protein identification and quantification. Targeted MS allows no new proteins to be identified because this approach requires the prior measurement of the targeted proteins by discovery proteomics. As a result, targeted proteomics can be a good choice when sufficient information has previously been acquired and the aim is not to identify the whole complement of proteins associated to a process or location, but rather to characterize coordinated changes in proteins abundance. ${ }^{25}$ For example, this approach can be used to examine the protein abundance profiles of lines differing in a given trait in order to identify or validate proteins whose abundance could be used as markers for selection of the trait concerned.

Selected Reaction Monitoring (SRM) is a sensitive MS technique allowing previously selected peptides in biological samples to be quantified. This method is a good choice for the highly accurate quantification of proteins in large cohorts of samples. ${ }^{25}$ SRM has been used to study the induction of certain enzymes in response to various chemical and biological stimuli, ${ }^{26}$ and also to reveal some aspects of symbiotic signalling in legumes. ${ }^{27}$ For example, a recent SRM-based study identified new markers for various traits in potato. ${ }^{24}$ While SRM is the current gold standard for quantitative estimation of proteins, the emerging Data-Independent Acquisition (DIA) technique has opened up a new dimension for comprehensive quantitative proteomics. ${ }^{28}$ In fact, DIA allows large numbers of peptides to be measured with modest sacrifices in sensitivity, selectivity and reproducibility relative to SRM, so it has been deemed a useful choice for large-scale targeted proteomics experiments. Whereas SRM is a target data acquisition method in which the data for the target molecules must be defined before acquisition, DIA acquires all data and the specific information needed is subsequently extracted..$^{29}$ Data-Dependent Acquisition (DDA) runs are processed by using a peptide spectrum matching pipeline; then, the resulting peptide IDs, spectra and retention times are used to build a spectral library of fragment ions and their relative abundance that can be reused in subsequent DIA runs performed with the same equipment. DIA analysis was recently used for proteome characterization of apple fruit, ${ }^{30}$ tomato fruit 
formation $^{31}$ and grapevine, ${ }^{32}$ and also for gluten profiling. ${ }^{33}$ To the authors' knowledge, however, this is the first time DIA has been used in combination with shotgun-DDA to identify peptide markers for resistance in pea crop.

This paper reports a two-step strategy for identifying defense-related key proteins of use as resistance markers in breeding selection programs. In the first step, two genotypes exhibiting a contrasting response to $P$. pinodes were selected for shotgun-DDA proteomic analysis. Using multivariate statistical analysis and comparing the results with those of previous gene expression studies allowed a list of candidate proteins as potential use as markers of resistance to Ascochyta blight to be compiled. In the second step, shotgun-DDA proteomics was used in combination with DIA analysis for the constitutive quantification of the target peptides in a RIL population segregated for resistance that was obtained by crossing the previous genotypes. Finally, a peptide marker panel for predicting pea-resistant phenotypes against $P$. pinodes was compiled.

\section{MATERIAL AND METHODS}

\section{Experimental design}

In this work, a strategy for identifying peptides potentially useful with a view to selecting pea plants resistant to $P$. pinodes was developed (Fig. 1). The list of target peptides consisted of proteins closely related the response of pea to $P$. pinodes and was compiled by using two genotypes with a contrasting response to $P$. pinodes, namely: the highly susceptible cultivar Messire ( $P$. sativum ssp. sativum) and the incompletely resistant cultivar P665 ( $P$. sativum ssp. syriacum). These cultivars have a typical disease rating value of $4.5-5$ and $2.5-3$, respectively, on a scale from 0 to 5 (Fig. 1A). ${ }^{10} \mathrm{~A}$ shotgun (LC-MSMS) proteomic experiment with no previous fractionation of samples was performed to identify the proteins that accumulated differentially under the established conditions (Fig. 1B). Peptides were selected by pairwise comparison and a multivariate statistical analysis was conducted of both inoculated and non-inoculated genotypes (Fig. 1C). Then, a second experiment was used to identify and quantify the previously selected peptides in 15 of the $111 \mathrm{~F}_{10}$ RIL families derived from the Messire x P665 cross -8 from the most resistant and 7 from the most susceptible lines - in the absence of pathogen, ${ }^{12}$ using a proteomics (MS1+DIA) strategy (Fig. 1D). Finally, the results of the statistical analysis of the data were used to select the peptides most 
significantly represented in the resistant lines and a list of putative peptide markers of resistance was compiled (Fig. 1E).

\section{Plant growth, inoculation and sampling time}

Pea seeds were germinated on wet fiber paper in Petri dishes and kept at $20{ }^{\circ} \mathrm{C}$ in the dark until roots were $4-5 \mathrm{~cm}$ long. Then, seedlings were transferred to pots $\left(250 \mathrm{~cm}^{3}\right)$ filled with a (1:1) sand-peat mixture and grown under controlled conditions: $(20 \pm 2)$ ${ }^{\circ} \mathrm{C}, 12 \mathrm{~h}$ dark/12 $\mathrm{h}$ light photoperiod and a photon flux density of $250 \mu \mathrm{molm}^{-2} \mathrm{~s}^{-1}$.

The first experiment involved 15 plants per genotype (Messire or P665). Six inoculated plants and six non-inoculated plants were used for leaf sampling, and another three to score disease symptoms on the scale of Roger and Tivoli ${ }^{34} 7$ days after inoculation. Plants were inoculated with a monoconidial $P$. pinodes isolate Co-99 obtained from pea plants with symptoms of Ascochyta blight in commercial fields at Córdoba (Spain). The isolate was confirmed to be $P$. pinodes and to contain no other pathogens causing Ascochyta blight from visual observation of the symptoms, morphological characterization of conidia and by Internal Transcribe Spacer (ITS) sequencing. ${ }^{35}$ The isolate was multiplied in Petri dishes containing Potato Dextrose Agar (PDA) medium at $20{ }^{\circ} \mathrm{C}$, using a photoperiod of $16 \mathrm{~h}$. A spore suspension was prepared according to Carrillo et $a .^{12}$ the concentration of which was further determined with a hemocytometer and adjusted to $5 \times 10^{5}$ spores per milliliter. Plants were inoculated at the 5-6 leaf stage ( 3 weeks old) by spreading the conidial suspension over the surface of the third and fourth leaf with the aid of a small paintbrush. Then, the plants were kept at high humidity in the dark for the first $24 \mathrm{~h}$ by using ultrasonic humidifiers operating for 15 min every 2 h, after which they were switched off. Finally, the plants were placed in a growth chamber with a $12 \mathrm{~h}$ light/ $12 \mathrm{~h}$ darkness photoperiod, at $250 \mu \mathrm{molm}^{-2} \mathrm{~s}^{-1}$.

A previous histological study was performed to characterize the timing of the different steps of $P$. pinodes infection under the conditions to be used in the experiments in order to select the most suitable sampling times for protein analysis. Messire plants were inoculated as described above and leaf samples were taken from them 12, 24, 36 and 48 hours after inoculation (hai). At those times, the proportion of germinated spores, penetration into the epidermis and formation of necrotic lesions in the mesophyll were determined in four leaflets per time point according to Carrillo et al. ${ }^{11}$ Based on 
the results, 24 and 48 hai, which corresponded to epidermal penetration and development of necrotic lesions in the mesophyll, respectively, were selected for further study (Supporting Information Fig. S1a and S1b). These time points were assumed to be the most suitable to harvest samples for proteomic analysis because previous studies ${ }^{36,11}$ suggested that resistance in P665 is characterized by the presence of an initial barrier hindering penetration of $P$. pinodes in the epidermis and further barriers restricting growth of the fungus in the mesophyll. The third and fourth leaves from each individual plant were collected and three biological replicates per condition were frozen in liquid nitrogen and stored at $-80{ }^{\circ} \mathrm{C}$ for subsequent analysis.

The second experiment involved non-inoculated plants belonging to $15 \mathrm{~F}_{10} \mathrm{RIL}$ segregating for resistance to Ascochyta blight and obtained by crossing the P665 and Messire cultivars. These choices were based on a previous study aimed at identifying QTL controlling resistance to $P$. pinodes in $P$. sativum that used a population consisting of 111 lines of the same RIL. ${ }^{37}$ Since proteomic experiments are subject to certain limitations such as the number of samples that can be analyzed in practice - replicates per condition included-, we used the 15 lines exhibiting the most extreme responses to $P$. pinodes (viz., the eight most resistant and the seven most susceptible lines). Four plants per line were grown under the conditions used in the first experiment albeit in the absence of pathogen. Also, a single sampling time corresponding to 17-days-old plants was used. As in the first experiment, the third and fourth leaves from three independent plants per line were collected, frozen in liquid nitrogen and stored at $-80{ }^{\circ} \mathrm{C}$ for later analysis.

\section{Protein extraction and digestion}

Pea leaves (200-300 mg fresh weight) from three independent replicates per condition (treatment, sampling time and genotype line) were crushed into a fine powder with liquid nitrogen in a precooled mortar and the powder was used to extract proteins according to Castillejo et $a l^{38}$

In-solution digestion was performed by using $50 \mu \mathrm{g}$ of protein and diluting samples to a final urea concentration of $1 \mathrm{M}$ with trypsin buffer containing $10 \%$ acetonitrile (ACN), $50 \mathrm{mM}$ ammonium bicarbonate and $2 \mathrm{mM} \mathrm{CaCl}_{2}$. Then, the samples were reduced with $5 \mathrm{mM}$ DTT and alkylated with $10 \mathrm{mM}$ iodoacetamide. Proteins were digested with proteomics-grade trypsin (Promega) at a final concentration of $12.5 \mathrm{ng} / \mu \mathrm{l}$ 
and incubated at $37^{\circ} \mathrm{C}$ overnight, the resulting digest being desalted by passage through a C18 cartridges from Scharlau (Barcelona, Spain). Finally, eluted peptides were vacuum-dried and dissolved in a mixture of $2 \% \mathrm{ACN}$ and $0.05 \%$ trifluoroacetic acid.

\section{Shotgun-DDA-LC-MS/MS analysis}

Protein analyses were conducted at the Proteomics Facility of the Research Support Central Service (SCAI) of the University of Cordoba. All peptides separations were done by nano-LC, using Dionex Ultimate 3000 nano UPLC equipment from Thermo Scientific (San Jose, CA, USA) and a C18 $75 \mu \mathrm{m} \times 50 \mathrm{~cm}$ Acclaim Pepmap column also from Thermo Scientific at $40{ }^{\circ} \mathrm{C}$ at a flow rate of $300 \mathrm{nl} / \mathrm{min}$. Peptides were previously concentrated and cleaned up on a $300 \mu \mathrm{m} \times 5 \mathrm{~mm}$ Acclaim Pepmap cartridge (Thermo Scientific) by using $2 \%$ ACN/0.05\% formic acid (FA) at $5 \mu \mathrm{l} / \mathrm{min}$ for $5 \mathrm{~min}$. A gradient of 120 min ranging from $95 \%$ solvent $\mathrm{A}(0.1 \% \mathrm{FA})$ to $80 \%$ solvent $\mathrm{B}(80 \%$ ACN, $0.1 \%$ FA) was used. Eluted peptide were ionized by using a nano-electrospray ionization source and analyzed on a trihybrid Thermo Orbitrap Fusion mass spectrometer from Thermo Scientific operated in the positive mode. A Top30 DataDependent Acquisition method with a maximum cycle time of $3 \mathrm{~s}$ was set up. MS1 scans of peptide precursors were acquired over the $m / z$ range $400-1500$, using a resolution of 120000 , at $\mathrm{m} / \mathrm{z} 200$ and a $4 \times 10^{5}$ ion count target threshold. Those precursor ions with a $2-5$ charge state were sampled for MS/MS by using a quadrupole isolation window of 1.2 Da. Monoisotopic precursor ions were CID-fragmented in the ion trap, which was set up as follows: automatic gain control, $2 \times 10^{3}$; maximum injection time, $300 \mathrm{~ms}$; and 35\% normalized collision energy. A dynamic exclusion time of $15 \mathrm{~s}$ and a tolerance of $10 \mathrm{ppm}$ around the selected precursor and its isotopes were used to avoid redundant fragmentations.

\section{Protein identification and statistical analysis}

The raw data obtained in the first experiment were processed by using the software Proteome Discoverer v. 2.1.0.81 from Thermo Scientific. MS2 spectra were searched with the SEQUEST engine against the protein FASTA files compiled by using a combination of the following databases: (1) the Uniprot-UniRef100 Pisum sativum database and Medicago truncatula (www.uniprot.org), (2) the legume-specific protein database LegProt (http://bioinfo.noble.org/manuscript-support/legumedb/), and (3) Pisum sativum unigene v.2 (https://www.coolseasonfoodlegume.org/ID328000). In 
silico peptide lists were generated by theoretical tryptic digestion allowing up to one missed cleavage, carbamidomethylation of cysteines as a fixed modification and oxidation of methionine as a variable modification. Precursor mass tolerance was 10 ppm and product ions were searched at a 0.1 Da tolerance. Peptide spectrum matches (PSM) were validated by using "percolator", an algorithm included in Proteome Discoverer, to discriminate correct and incorrect peptide spectrum matches and calculate accurate statistics based on $q$-values at a false discovery rate (FDR) of $1 \%$. For identification, peptides were grouped into proteins according to the law of parsimony and filtered to $\mathrm{FDR}=1 \%$ and $\mathrm{XCorr} \geq 2$.

Proteins were quantified in relative terms from the Spectra Count (SC), which is the total number of MS/MS spectra identified for a particular peptide represented by its precursor ion in a sample. The abundance of a peptide is thus measured as the number of peptide spectrum matches (PSM) events. Proteome Discoverer software creates protein groups from the identified PSMs and considers the presence of proteins that have shared peptides. The software excludes all protein groups having no unique peptides (i.e., peptides that are not shared with any other protein). Shared peptides are quantified by dividing their assigned values by the number of proteins in which they are present. Protein values were normalized according to the Normalized Spectral Abundance Factor (NSAF), a method that accounts for protein size and variability between runs to normalize relative protein abundance between samples. ${ }^{39}$ In this work, we used 3 replicates per experimental condition for statistical analysis. The criteria used to deem a protein as change were as follows: $(a)$ the protein was consistently present or absent in all three replicates for a condition; $(b)$ it exhibited statistically significant differences ( $T$-test, $p \leq 0.05$ ) between genotypes or treatments; and $(c)$ the change was at least two-fold. The whole data set was additionally subjected to multivariate factor analysis with the software SPSS v.23. Data were checked to be amenable to factor analysis by using the Kaiser-Meyer-Olkin (KMO) ${ }^{40}$ measurement of sampling adequacy and Bartlett's test of sphericity. ${ }^{41}$ The procedure included Principal Component Extraction and Oblique Rotation.

\section{Functional classification and prediction of interactions between proteins}

Functional annotations and molecular functions were retrieved from Uniprot and Mapman tool v.3.5.1. Protein-protein interaction networks of stress-induced proteins were generated by using the webtool STRING10 (http://string-db.org). The protein 
homologs in Arabidopsis were analyzed by sequence BLASTing of the TAIR database (http://www.arabidopsis.org/Blast/index.jsp), followed by application of STRING10 to develop a proteome-scale interaction network. ${ }^{42}$

\section{Targeted data analysis for selection of putative peptide markers}

The peptides from proteins that fulfilled the following criteria were selected as target peptides by comparing the response of the Messire and P665 genotypes to P. pinodes: (a) proteins significantly $(p \leq 0.05)$ induced in the resistant genotype (P665) relative to the susceptible genotype (Messire) upon inoculation with $P$. pinodes; $(b)+2$ and +3 charged peptides with a robust and reproducible high-quality peak shape in all replicates; $(c)$ proteotypic peptides (viz., the peptide sequence marked for protein specificity as far as the present annotation information allows). A shotgun proteomics (DDA LC-MS/MS) experiment was used to quantify the selected target peptides in the 15 RIL families by using the precursor ions MS1. Liquid chromatography analyses were done with the mass spectrometer operating in a Top30 Data-Dependent mode. The resulting DDA data, which were obtained from individual analyses of ca. $200 \mathrm{ng}$ of sample, were used in the database searches needed to identify proteins present in the samples and to build a spectral library with the software Skyline ${ }^{43}$ (https://skyline.ms), which could was then used to extrac the target peptides from the DIA data. The chromatographic conditions used were the same as in the shotgun-DDA analysis but runs were much shorter (90 $\mathrm{min})$.

Peptides were quantified by integrating the chromatographic peak areas of the fragment ions in Skyline. The conditions used for relative quantification of MS1ions were a mass tolerance of $0.055 \mathrm{~m} / z, 0.5 \mathrm{~m} / \mathrm{z}$ for library peak integration and a resolution of 120000 at $\mathrm{m} / \mathrm{z}$ 200. Peptide values were subsequently subjected to statistical significance analysis by using the external tool MS Stats ${ }^{44}$ included in Skyline. Those ions exhibiting a low or inconsistent signal between replicates in Skyline were quantified with the software MaxQuant v.1.5.1.245 on the same database, using the default "instrument" and "LFQ" (label-free quantification) settings, and the peptide modifications as in SEQUEST. Data were normalized by equalizing the medians of the intensity values and applying a $\log 2$-transformation. Then, SPSS was used to perform a multivariate factor analysis based on the quantitative values for the peptides (specifically, the precursor ions for the target peptides), in order to assess the degree of association between the peptides and the resistant trait. 
The results of the MS1 analysis were confirmed by using a DIA strategy based on targeted data analysis at the fragment ion level (MS2). Amounts of ca. $200 \mathrm{ng}$ of 6 segregating lines were used in each case. The mass spectrometer was operated with a High-Resolution Accurate Mass (HR/AM) MS1 scan at a resolution of 120000 , followed by 40 DIA scans of $10 \mathrm{~m} / \mathrm{z}$ isolation windows at a resolution of 30000 at $\mathrm{m} / \mathrm{z}$ 200. In this way, the precursor mass range from $\mathrm{m} / z 500$ to 900 was spanned throughout the chromatographic elution profile. MS2 DIA data were extracted with Skyline. Only unique tryptic peptides having no missed cleavages and no methionine sequence motifs were considered. The processing method for DIA analyses was applied under identical conditions as the DIA acquisition method. Thus, "no deconvolution" and "overlap" were set to ON. MS1 filtering was done by fixing 3 isotopic peaks at a resolution of 120 000. Only those scans completed within the first $5 \mathrm{~min}$ were considered for MS/MS alignment and for peak integration both $b$ and $y$ ions series; also, data extraction was based on parent ions. Instrument mass tolerance was $0.055 \mathrm{~m} / \mathrm{z}$, ion match tolerance 0.5 $\mathrm{Da}$ and the seven most intense ions were used for matching with the library. The MS proteomics data were deposited with the dataset identifier PXD009351 in the ProteomeXchange Consortium via the PRIDE ${ }^{46}$ partner repository.

\section{RESULTS}

\section{Disease assessment}

Disease rating (DR) was scored on the 0-5 scale of Roger and Tivoli. ${ }^{34}$ One week after inoculation, the Messire genotype was strongly affected by $P$. pinodes (average DR, 4.5; range, 3.5-5; variance, 0.4). In fact, this genotype exhibited extensive coalesced lesions in addition to dehydration or necrosis over most of its leaf area (Supporting Information Fig. S1c). On the other hand, the P665 genotype was highly resistant (ANOVA $p<0.05$ ) and only exhibited small flecks or lesions (average DR, 2.8; range, 2.5-3; variance, 0.06), which is consistent with the incomplete resistance observed in previous studies ${ }^{10}$ (Supporting Information Fig. S1d).

\section{Shotgun-DDA proteomic analysis and selection of target peptides}

A total of 1375 proteins were identified of which 653 differed significantly between genotypes (Messire and P665) and treatments (control and inoculation). Table S1 (Supporting Information) shows the whole dataset of differential proteins, and Fig. 2A and Table S2a (Supporting Information) the significantly $(p \leq 0.05)$ over- and down- 
accumulated ratios (2-fold change) between treatments and genotypes. A Principal Component Analysis (PCA) allowed data to be grouped in terms of genotype, sampling time and treatment (control and inoculated) (Fig. 2B). The first two principal components jointly accounted for more than $80 \%$ of the biological variability. Fig. 2C shows unique proteins and those shared between genotypes or treatments at each sampling time in the form of Venn diagrams. As can be seen, inoculation increased the number of unique proteins in both genotypes at the second sampling time (48 hai).

All significantly modified proteins were functionally categorized by using the Uniprot database and Mapman tool v.3.5.1 (Supporting Information Table S2a). Fig. 3A shows the significantly up- and down-accumulated proteins between genotypes and treatments (653) by functional category. The pie chart in Fig. 3B shows the proteins categories induced in response to $P$. pinodes inoculation (355). The major functional categories, which jointly accounted for nearly one-half of induced proteins, were translation, redox, folding/degradation, and energy metabolism proteins.

The focus was placed on proteins involved in the defense against $P$. pinodes, which were initially assumed to be those differentially accumulating in the resistant genotype (P665) but not in the susceptible genotype (Messire) upon inoculation (Supporting Information Table S2b). Such was the case with 83 proteins of which 75 accumulated in inoculated P665 plants but not in non-inoculated plants. These 83 differentially accumulated proteins were used to select target peptides. The procedure involved identifying proteotypic peptides derived from them in the $15 \mathrm{RIL}$ lines at the constitutive level. As can be seen from Fig. 3C, the proteins spanned the main functional categories protein synthesis/degradation (42\%), and redox and stress-related (21\%). Fig. 4 shows a MapMan overview of the functional distribution and relative abundance ratio of the proteins in response to inoculation. A significant increase in proteins involved in energy production pathways (oxidative pentose phosphate, mitochondrial electron transport and TCA), secondary metabolism, redox and stress response, protein regulation, signaling and cell organization was observed.

\section{Selection of putative peptide markers of resistance by targeted data analysis}

A list of peptides from the 83 selected proteins was compiled for use in a second targeted data analysis. The list included 320 peptides from the dataset of the shotgunDDA analysis (Supporting information Table S3) that were selected as potential 
candidates for marker selection as described under Material and Methods, and quantified in the $15 \mathrm{~F}_{10}$ RIL segregating population. ${ }^{37}$ Of the 320 peptides, 117 were quantified by using the library built as described in Material and Methods (Supporting Information Table S4). The degree of association of the 117 peptides to the resistance trait in the RIL families was assessed by multivariate factor analysis of the quantitative values for the peptides (viz., normalized intensity values). As can be seen in Fig. S2 (Supporting Information), resistant lines tended to group, with the first three factors (Sum of Squares (SS) loadings > 1) jointly accounted for $82 \%$ of the total variance. The peptides were assigned unrotated factor loadings, so the greater the value was, the stronger was its contribution to explaining the variability. Those peptides with loadings equal or greater than an absolute value of 0.7 in factors F1 to F3 were assumed to be significantly related to resistance. Table 1 includes information about the 24 most relevant peptides, which were present in 15 different proteins. Interestingly, of the 15 proteins, 9 (15 peptides) were significantly more abundant in the resistant genotype P665 than they were in the susceptible genotype (Messire) at the constitutive level (noninoculated plants) (Supporting Information Table S3b). Under inoculation, the other 6 proteins in the panel were better represented in P665 than in Messire.

A DIA analysis was carried out to quantify the 320 selected peptides by sequentially acquiring fragment-ion spectra with overlapping precursor isolation windows (Fig. 5). Figure S3 (Supporting Information) illustrates the reproducibility in retention time (RT) along all the lines for each of the 24 peptides and Fig. S4a shows the peak groups extracted from the results of the DDA and DIA analyses on 6 peptides from the marker panel. As can be seen in Fig. S4b, a similar pattern of peak ion intensity was observed with both strategies (DDA and DIA). This result testifies to the suitability of the DDA strategy (viz., quantifying MS1 precursor ions by shotgun-DDA analysis) for selecting putative marker peptides.

\section{Protein-protein interactions unravel the defensive response of pea to Ascochyta}

\section{blight}

Potential relationships among the 83 significantly induced proteins were explored by generating protein-protein interaction networks using the web-tool STRING10 (http://string-db.org). As can be seen in Fig. 6, the red nodes that clustered together most of them corresponding to ribosomal proteins involved in protein synthesis - were strongly connected. This protein group was also linked to other functional groups but mostly to the redox (glutathione S-transferase, peroxidase, thioredoxin, glutaredoxin), 
protein degradation (CLP proteases), defense (osmotin, disease resistance response protein Pi176) and energy metabolism (mitochondrial electron transfer) categories. Several proteins of signaling (calmodulin, 14-3-3-like), transport (ADP/ATP carrier), and elongation factors linked this group of ribosomal proteins to other functional groups including mitochondrial electron transport, redox, degradation and sulfite metabolism proteins. Most of the proteins in the interaction network were somehow related to others.

\section{DISCUSSION}

The results of the proteomic analysis revealed that inoculation with $P$. pinodes triggered different defense mechanisms in the two genotypes; this may have been the source of resistance in P665 and susceptibility in Messire. The underlying mechanisms are discussed and compared below with others established from previous transcriptomic analyses. As can be seen in Table S2 (Supporting Information), 83 differentially represented proteins accumulated to a great extent in the resistant genotype in response to $P$. pinodes; most such proteins were previously found to be expressed at the genomic level in response to Ascochyta in similar systems. Below are discussed and compared the results of this work with those of previous studies.

\section{Regulation of protein synthesis and energy production to offset the cost of resistance}

Eight of the peptides proposed as potential markers belonged to four proteins in the protein degradation category, namely: ATP-dependent Clp protease proteolytic subunit (contig2217), 26S protease regulatory subunit 6A (contig20430) and subunit 11 (contig4092), and leucine aminopeptidase 2 (contig3912). Proteases have been associated to the defense against predators through degradation of exogenous proteins; ${ }^{47}$ also, they may degrade proteins produced by $P$. pinodes to infect the plant. Recently, two such proteases (viz., ATP-dependent Clp protease and leucine aminopeptidase) were identified to be increased in the resistant pea genotype P665 in response to aphids attack. ${ }^{48}$ Also, previous studies have shown proteases to be involved in preventing parasite attack on pea plants and the model legume Medicago truncatula. ${ }^{49-51}$

Here, we found a close relationship between the transport protein ADP, ATP carrier protein (AAC1; contig21564) and several ribosomal proteins (contig04805, contig2390, contig03572) (Fig. 6), whose peptides have also been deemed potential markers (Table 1). In addition, AAC1 is related to a group of enzymes involved in the 
mitochondrial respiratory chain that may be triggered in response to increased cell energy requirements. Ribosomal proteins are also linked to a group of carbohydrate metabolism proteins (TCA, glycolysis) such as malate dehydrogenase, isocitrate dehydrogenase or phosphoglycerate mutase (Fig. 6). A previous proteomic study on the pea- $P$. pinodes system revealed similar effects. Also, the resistant pea cultivar was found to exhibit increased levels of proteins involved in energy and amino acid metabolism, probably to offset the cost of resistance. ${ }^{52}$ More efficient energy use could make P665 more resistant without major reductions in yield, but this hypothesis requires experimental testing.

\section{Cell wall reinforcement and detoxification to restrict pathogen growth}

Previous microarray experiments ${ }^{13}$ identified structural genes of the primary cell wall that were up-regulated in P665 relative to Messire in response to $P$. pinodes. Such genes included caffeic acid O-methyltransferase (COMT) gene, which is involved in the synthesis of lignin. Coram and Pang53 previously found a Caffeoyl-CoAmethyltransferase in a chickpea EST library set up to identify defense-related encoding proteins in response to Ascochyta blight. In this work, we found a COMT protein to be significantly increased in response to Ascochyta in both genotypes, a result that was previously observed in the resistant genotype (P665) only.

Pectinesterases or pectin methylesterases (PME) are ubiquitous enzymes that modify the degree of methylesterification of pectins, the major components of plant cell walls. These proteins were found to accumulate markedly in the resistant genotype in response to the pathogen. Four peptides selected as potential markers in the resistant RIL population corresponded to this protein (O24298). Modifications in pectin structure have been associated to changes in cellular adhesion, plasticity, $\mathrm{pH}$, and ionic contents of the cell wall, which influence plant development and stress responses. ${ }^{54}$ Activity changes in pectinesterases, and associated changes in the degree of methylesterification of pectins in cell walls, were previously found to correlate to modifications in plant susceptibility to biotic and abiotic stresses. ${ }^{55-57}$ Thus, these proteins are also significantly increased in the resistant pea genotype (P665) in response to drought stress. ${ }^{38}$

In addition to our proteomic results, histological studies ${ }^{36}$ have shown $P$. pinodes to be largely unsuccessful in colonizing P665 because most infection units stop at the epidermal cells and fail to reach the mesophyll. Wall reinforcement was previously found to play a role in pea resistance to $P$. pinodes. $9,14,58$ In fact, 
reinforcement cell walls may help develop a physical barrier to prevent epidermal penetration of $P$. pinodes and expansion in mesophyll, thereby hindering diffusion of pathogenic toxins.

The ribosomal protein group was also related to redox, defense, signaling, proteins of degradation and sulfur metabolism categories. Many of the peptides in the marker panel (Table 1) contained such proteins, which included calmodulin (P59220), cytochrome c oxidase (Q0KKQ5), TIC110 (O24303) and sulfite reductase (Q75NZ0).

Perception of pathogen-associated molecules triggers defense responses via signal transduction cascades and activation of many genes. ${ }^{53}$ The signals for the defense mechanisms include expression of transcription factors and protein kinases, and an increase in cytosolic calcium levels. ${ }^{9}$ In recent years it has become apparent that reactive oxygen species (ROS) produced by plants are signaling molecules for control processes such as programmed cell death, biotic and abiotic stress responses, and systemic signaling. Several components involved in the signal transduction pathways of ROS-sensing plants were recently identified. For example, activation of calmodulin and MAP-kinase cascade triggers or suppresses some transcription factors that regulate the response of plants to oxidative stress. ${ }^{60}$ Some of the proteins identified here are involved in signal recognition and transduction pathways. Such is the case with calmodulin, 14-3-3 like protein, kinases and various transcription factors, all of which accumulated differentially in P665 in response to $P$. pinodes. Consistent with our results, previous microarray ${ }^{13}$ and superSAGE ${ }^{14}$ experiments revealed up-regulation of the genes encoding these proteins in the resistant pea genotype (P665).

As can be seen in Fig. 6, calmodulin was associated to 14-3-3 like protein, which is closely connected to defense proteins such as GSH and the disease resistance response protein MLP423. 14-3-3 plant proteins bind to many pathogens-secreted effectors. In plant-fungus interactions, these proteins play a potential role as receptors of fungal toxins. ${ }^{61}$ Recent studies have suggested that 14-3-3 proteins are involved in the responses to environmental stress through regulation of ion channels. Thus, Yan et $a l .{ }^{62}$ found overexpression of Arabidopsis 14-3-3 in cotton by and, more recently, in pea plants infected by Fusarium oxysporum. ${ }^{63}$ Interestingly, our protein network included transport protein TIC110, which was closely related to the group of defense proteins. The chloroplast envelope anion channel-forming TIC110 family consists of proteins present in the inner chloroplast envelope membrane. This is a protein import-related anion-selective channel. 
Calmodulin was also closely related to two reductases enzymes, namely: ferredoxin-NADP reductase (FNR) and sulfite reductase [ferredoxin] (SiR). In photosynthetic electron transport, FNR transfers electrons from ferredoxin (Fd) to $\mathrm{NADP}^{+}$. Both NADPH and reduced $\mathrm{Fd}$ are required for reductive assimilation and light/dark activation/deactivation of enzymes, which thus connect photosynthetic electron transport to chloroplast redox metabolism. Although the precise mechanism is unclear, a relationship between FNR content and tolerance to oxidative stress has been unequivocally established. ${ }^{64} \mathrm{SiR}$ has been associated to oxidative stress tolerance, which it probably favors by maintaining sulfite homeostasis through glutathione levels. ${ }^{65}$ Glutathione (GSH) is known to be a major reduced sulfur sink and a regulator of sulfur assimilation; ${ }^{66}$ also, it plays a central role in protecting plants from oxidative stress. ${ }^{67,68}$ Recently, a substantial reduction in GSH levels in impaired-SiR tomato plants was found to result in early leaf senescence. ${ }^{69}$ Whether this protein is involved in the response to oxidative stress is unknown, however. Previous transcriptomic studies revealed up-regulation of some members of the Glutathione S-transferase (GST) gene family in the resistant pea genotype P665 upon inoculation with $P$. pinodes. ${ }^{13}$ GSTs are involved in various metabolic processes and also in the detoxification of a wide range of compounds including microbial toxins. ${ }^{70}$ Interestingly, our protein network revealed a relationship between ribosomal proteins, transcription factors and a group of redox proteins including GSTs, glutaredoxins, thioredoxin and peroxidase, all of which were significantly increased in response to Ascochyta.

\section{Other defense mechanisms}

Other proteins closely involved in pea resistance to $P$. pinodes included defensin, endoglucanase inhibitor and endochitinase. Previous studies on the pea- $P$. pinodes interaction suggested activation of $\beta$-1,3-glucanase and chitinases, ${ }^{14,71}$ and production of superoxide anion, ${ }^{72}$ among other defense responses in pea. Also, some authors have proposed candidate genes such as defensin and endochitinase for pea resistance to $P$. pinodes. ${ }^{13,21}$

Based on the foregoing, the response of pea to $P$. pinodes may involve various mechanisms that make it resistant to the fungus. A major redox response is probably triggered to detoxify fungal toxins that is accompanied by strong regulation of protein synthesis and energy production. In addition, growth of $P$. pinodes in the mesophyll is seemingly inhibited by altering the composition of cell walls. These defense 
mechanisms were especially apparent at the last sampling time (48 hai), once the pathogen had penetrated the leaf epidermis and reached the mesophyll. For the first time, a panel of peptides as putative markers of resistance to $P$. pinodes is proposed here. As shown by our results, most of the proteins induced in response to the pathogen were present at the constitutive level in the resistant genotype; also, they were highly represented in the resistant group of the segregating lines after 10 generations. However, these results should be taken cautiously and would require validation if they were to be extrapolated to other experimental systems.

The proposed markers could be useful to combine the resistance mechanisms of P665 with those found in other genotypes into a single variety of increased resistance. Investigating gene co-segregation in the proteins identified here and previously reported resistance QTLs ${ }^{37}$ in the parental lines from which the mapping populations were developed might help provide plant breeders with new markers for incorporation into marker-assisted breeding programs with a view to improving pea resistance to Ascochyta.

\section{CONCLUSIONS}

Targeted proteomics has to date scarcely been used to identify markers for predicting important phenotypes. To our knowledge, this is the first time that a targeted proteomic (shotgun-DDA combined DIA) based data analysis strategy has been used to identify potential markers of resistance to $P$. pinodes. A defense mechanism of pea against Ascochyta blight based on the results is proposed. The mechanism involves reinforcement of cell walls to hinder growth of the pathogen within cells, detoxification of fungal toxins via a redox response and tight regulation of protein synthesis, and energy production to offset the cost of resistance. From a methodological point of view this strategy allowed us to select a panel of peptides closely related to pea resistance to Ascochyta blight. Targeted proteomic data analysis therefore provides a promising method for markers selection and can open up new avenues for plant breeding. Also, it can be useful to identify new markers for predicting important traits in other crops and validating potentially significant biomarkers in plant research. 


\section{FIGURE CAPTIONS}

Figure 1. Schematic workflow for marker selection. (A) Susceptible and resistant plant inoculation; (B) shotgun-DDA proteomics for identification of differential proteins; (C) univariate and/or multivariate statistics to identify significantly changed proteins between genotypes and induced in response to inoculation; (D) quantitative proteomics (shotgun-DDA + DIA) analysis in a segregating (non-inoculated) population derived from a cross between the two genotypes; (E) selection of peptide markers based on the degree of association between the peptides and the resistance trait determined by statistical analysis.

Figure 2. (A) Number of proteins significantly altered in abundance $(p \leq 0.05)$ up- or down-accumulated, represented as positive and negative respectively, comparing noninoculated genotypes, and also in response to P. pinodes inoculation. P: P665 genotype, M: Messire genotype, C: Control (non-inoculated), I: Inoculated, 1: 24 hai, 2: 48 hai; (B) Principal Component Analysis (PCA) showing associations between samples. A short distance between samples in the component space is indicative of similarity in abundance protein profiles; (C) Venn diagrams representing significantly changed proteins between genotypes and in response to $P$. pinodes.

Figure 3. (A) Functional categories of 653 pea proteins given as the number of those significantly altered in abundance (one-way ANOVA, $p \leq 0.05$ ) after inoculation. P: P665 genotype, M: Messire genotype, C: Control (non-inoculated), I: Inoculated, 1: 24 hai, 2: 48 hai; (B) Functional categorization as a percentage of the 355 differential proteins on both genotypes under $P$. pinodes inoculation; (C) Functional categories as percentage of the 83 induced proteins in the resistant genotype (P665) in response to $P$. pinodes.

Figure 4. MapMan overview: functional distribution and relative abundance ratio of the 83 proteins ( $\log 10$ of the spectral count normalized by protein weight) identified when several conditions were compared: PI/MI (P665 inoculated versus Messire inoculated), PI/PC (P665 inoculated versus P665 control). Numbers 1 and 2 correspond to sampling times 24 and 48 hai, respectively. The strength of the color indicates the protein abundance.

Figure 5. Representative MS1 fragment ion of a target precursor (A) also monitored by Data-Independent Acquisition (DIA) analysis (B). 
Figure 6. Protein interaction network analysis of the 83 induced proteins in the resistant pea genotype (P665) in response to $P$. pinodes, represented by the homologous proteins from Arabidopsis. Proteins are grouped according the annotated biological process. The protein network in the confidence view generated by STRING database is shown. Stronger associations are represented by thicker lines.

\section{SUPPORTING INFORMATION}

Figure S1. Disease assessment. Histological observations of $P$. pinodes infection process (upper pictures): $P$. pinodes spore penetrating epidermis of Messire pea genotype 24 hours after inoculation (hai). The arrow shows the penetration point (a); necrotic lesions produced by $P$. pinodes in mesophyll of Messire 48 hai (b). Symptoms (lower pictures) caused by P. pinodes in P665 (c) and Messire (d) pea genotypes one week after inoculation.

Figure S2. Multivariate factor analysis to define association of the RIL families based on the normalized intensity values of the target peptides.

Figure S3. Retention Time (RT) reproducibility recorded on the 24 peptides selected. Box widths, handle bars and horizontal lines indicate peak group integration boundaries and peak apex respectively.

Figure S4. a) Extracted peak groups from shotgun-DDA (precursor ion, left) and DIA (transitions ions, right) assays measured in 6 peptides of the marker panel; b) Peak area of precursors and transitions were measured in 6 lines $(103,12,3,44,68,84)$.

Table S1. Dataset of proteins identified by shotgun-DDA proteomic analysis.

Table S2. a) Fold change ratios of the significantly changed proteins classified by functional categories; b) Fold change ratios of the induced proteins in response to Ascochyta classified by functional categories.

Table S3. Dataset of peptides identified by shotgun-DDA proteomic analysis.

Table S4. Quantitation of peptide candidates for marker selection in the segregating RIL population. 


\section{ACKNOWLEDGEMENT}

I would like to thank Dr. Elena Prats for providing facilities and support, Dr. Antonio Archidona-Yuste for collaboration in the statistical analysis of the data, and Dr. Palak Chaturvedi for reviewing the manuscript. This work was supported by EU-FP7LEGATO and Spanish AGL2017-82901-R projects. MAC is also grateful for the contract "Ramón y Cajal (RYC-2017-23706) program" of the Spanish Ministry of Science, Innovation and Universities. 


\section{REFERENCES}

1. Rubiales, D.; Fondevilla, S.; Chen, W.; Gentzbittel, L.; Higgins, T. J. V.; Castillejo, M. A.; Singh, K. B.; Rispail, N., Achievements and challenges in legume breeding for pest and disease resistance. Crit Rev Plant Sci 2015, 34, 195236.

2. Tivoli, B.; Banniza, S., Comparison of the epidemiology of ascochyta blights on grain legumes. In: (eds) In Ascochyta blights of grain legumes., Tivoli, B.; Baranger, A.; Muehlbauer, F. J.; Cooke, B. M., Eds. Springer: Netherlands, 2007; pp 59-76.

3. Wallen, V. R., Field evaluation and the importance of the Ascochyta complex on peas. Can J Plant Sci 1965, 45, 27-33.

4. Lawyer, A. S., Diseases caused by Ascochyta spp. In The compendium of pea diseases, Hagedorn, D. J., Ed. American Phytopathological Society: Wisconsin, 1984; pp 11-15.

5. Rubiales, D.; Pérez de Luque, A.; Cubero, J. I.; Sillero, J., Crenate broomrape (Orobanche crenata) infection in field pea cultivars. Crop Prot 2003, 22, 865872.

6. Rubiales, D.; Fernández-Aparicio, M.; Moral, A.; Barilli, E.; Sillero, J. C.; Fondevilla, S., Disease resistance in pea (Pisum sativum L.) types for autumn sowings in Mediterranean environments. Czech J Genet Plant 2009, 45, 135-142.

7. McMurray, L. S.; Davidson, J. A.; Lines, M. D.; Leonforte, A.; Salam, M. U., Combining management and breeding advances to improve field pea (Pisum sativum L.) grain yields under changing climatic conditions in south-eastern Australia. Euphytica 2011, 180, 69-88.

8. Xue, A. G.; Warkentin, T. D., Partial resistance to Mycosphaerella pinodes in field pea. Can J Plant Sci 2001, 81, 535-540.

9. Wroth, J. M., Possible role for wild genotypes of Pisum spp. to enhance ascochyta blight resistance in pea. Aust J Exp Agr 1998, 38, 469-479.

10. Fondevilla, S.; Avila, C. M.; Cubero, J. I.; Rubiales, D., Response to Mycosphaerella pinodes in a germplasm collection of Pisum spp. Plant Breeding 2005, 124, 313-315.

11. Carrillo, E.; Rubiales, D.; Pérez-de-Luque, A.; Fondevilla, S., Characterization of mechanisms of resistance against Didymella pinodes in Pisum spp. Eur J Plant Pathol 2013, 135, 761-769.

12. Carrillo, E.; Satovic, Z.; Aubert, G.; Boucherot, K.; Rubiales, D.; Fondevilla, S., Identification of quantitative trait loci and candidate genes for specific cellular resistance responses against Didymella pinodes in pea. Plant Cell Rep 2014, 33, 1133.

13. Fondevilla, S.; Küster, H.; Krajinski, F.; Cubero, J. I.; Rubiales, D., Identification of genes differentially expressed in a resistant reaction to Mycosphaerella pinodes in pea using microarray technology. BMC Genomics 2011, 12, 28.

14. Fondevilla, S.; Rotter, B.; Krezdorn, N.; Jüngling, R.; Winter, P.; Rubiales, D., Identification of genes involved in resistance to Didymella pinodes in pea by deepSuperSAGE transcriptome profiling. Plant Mol Biol Rep 2014, 32, 258-269.

15. Wroth, J.M., Evidence suggests that Mycosphaerella pinodes infection of Pisum sativum is inherited as a quantitative trait. Euphytica 1999, 107, 193-204. 
16. Timmerman-Vaughan, G.M.; Frew, T.J.; Russell, A.C.; Khan, T.; Butler, R.; Gilpin, M.; Falloon, K., QTL mapping of partial resistance to field epidemics of ascochyta blight of pea. Crop Sci 2002, 42, 2100-2111.

17. Timmerman-Vaughan, G.M.; Frew, T.J.; Butler, R.; Murray, S.; Gilpin, M.; Falloon, K.; Khan, T., Validation of quantitative trait loci for Ascochyta blight resistance in pea (Pisum sativum L.) using populations from two crosses. Theor Appl Genet 2004, 109, 1620-1631

18. Tar'an, B.; Warkentin. T.; Somers, D.J.; Miranda, D.; Vandenberg, A.; Blade, S.; Penner, G., Quantitative trait loci for lodging resistance, plant height and partial resistance to mycosphaerella blight in field pea (Pisum sativum L.). Theor Appl Genet 2003, 107, 1482-1491.

19. Prioul, S.; Frankewitz, A.; Deniot, G.; Morin, G.; Baranger, A., Mapping of quantitative trait loci for partial resistance to Mycosphaerella pinodes in pea (Pisum sativum L.), at the seedling and adult plant stages. Theor Appl Genet 2004, 108, 1322-1334.

20. Zhang, R.; Hwang, S. F.; Chang, K. F.; Gossen, B. D.; Strelkov, S. E.; Turnbull, G. D., Blade SF Genetic resistance to in 558 field pea accessions. Crop Sci 2006, 46, 2409-2414.

21. Prioul-Gervais, S.; Deniot, G.; Receveur, E.-M.; Frankewitz, A.; Fourmann, M.; Rameau, C.; Pilet-Nayel, M.-L.; Baranger, A., Candidate genes for quantitative resistance to Mycosphaerella pinodes in pea (Pisum sativum L.). Theor Appl Genet 2007, 114, 971-984.

22. Jha, A.B.; Tar'an, B.; Stonehouse, R.; Warkentin, T.D., Identification of QTLs associated with improved resistance to ascochyta blight in an interspecific pea recombinant inbred line population. Crop Sci 2016, 56, 2926-2939.

23. Fondevilla, S.; Almeida, N. F.; Satovic, Z.; Rubiales, D.; Patto, M. C. V., Cubero, J. I.; Torres, A. M., Identification of common genomic regions controlling resistance to Mycosphaerella pinodes, earliness and architectural traits in different pea genetic backgrounds. Euphytica 2011, 182 43-52.

24. Chawade, A.; Alexandersson, E.; Bengtsson, T.; Andreasson, E.; Levander, F., Targeted Proteomics Approach for Precision Plant Breeding. J Proteome Res 2016, 15, 638-46.

25. Domon, B.; Aebersold, R., Options and considerations when selecting a quantitative proteomics strategy. Nat Biotechnol 2010, 28, 710-21.

26. Zulak, K. G.; Lippert, D. N.; Kuzyk, M. A.; Domanski, D.; Chou, T.; Borchers, C. H.; Bohlmann, J., Targeted proteomics using selected reaction monitoring reveals the induction of specific terpene synthases in a multi-level study of methyl jasmonate-treated Norway spruce (Picea abies). Plant J 2009, 60, 1015-30.

27. Van Ness, L. K.; Jayaraman, D.; Maeda, J.; Barrett-Wilt, G. A.; Sussman, M. R.; Ane, J. M., Mass Spectrometric-Based Selected Reaction Monitoring of Protein Phosphorylation during Symbiotic Signaling in the Model Legume, Medicago truncatula. PLoS One 2016, 11, e0155460.

28. Meyer, J. G.; Schilling, B., Clinical applications of quantitative proteomics using targeted and untargeted data-independent acquisition techniques. Expert Rev Proteomics 2017, 14, 419-429.

29. Borràs, E.; Sabidó, E., What is targeted proteomics? A concise revision of targeted acquisition and targeted data analysis in mass spectrometry. Proteomics 2017, 17, 17-18.

30. Buts, K.; Michielssens, S.; Hertog, M. L.; Hayakawa, E.; Cordewener, J.; America, A. H.; Nicolai, B. M.; Carpentier, S. C., Improving the identification 
rate of data independent label-free quantitative proteomics experiments on nonmodel crops: a case study on apple fruit. J Proteomics 2014, 105, 31-45.

31. Martin, L. B.; Sherwood, R. W.; Nicklay, J. J.; Yang, Y.; Muratore-Schroeder, T. L.; Anderson, E. T.; Thannhauser, T. W.; Rose, J. K.; Zhang, S., Application of wide selected-ion monitoring data-independent acquisition to identify tomato fruit proteins regulated by the CUTIN DEFICIENT2 transcription factor. Proteomics 2016, 16, (15-16), 2081-94.

32. Riebel, M.; Fronk, P.; Distler, U.; Tenzer, S.; Decker, H., Proteomic profiling of German Dornfelder grape berries using data-independent acquisition. Plant Physiol Biochem 2017, 118, 64-70.

33. Bromilow, S. N.; Gethings, L. A.; Langridge, J. I.; Shewry, P. R.; Buckley, M.; Bromley, M. J.; Mills, E. N., Comprehensive Proteomic Profiling of Wheat Gluten Using a Combination of Data-Independent and Data-Dependent Acquisition. Front Plant Sci 2016, 7, 2020.

34. Roger, C.; Tivoli, R., Spatio temporal development of pynidia and perithecia and dissemination of spores of Mycosphaerella pinodes on pea (Pisum sativum). Plant Pathol 1996, 45, 518-528.

35. Barilli, E.; Cobos, M.J.; Rubiales, D., Clarification on host range of Didymella pinodes the causal agent of pea Ascochyta blight.Front Plant Sci 2016, 7,592.

36. Fondevilla, S. Identification and characterization of sources of resistance to Mycosphaerella pinodes in Pisum spp. University of Córdoba, 2000.

37. Fondevilla, S.; Rubiales, D.; Zatovic, S.; Torres, A. M., Mapping of quantitative trait loci for resistance to Mycosphaerella pinodes in Pisum sativum subsp. syriacum. Mol Breeding 2008, 21, 439-454.

38. Castillejo, M. A.; Iglesias-García, R.; Wienkoop, S.; Rubiales, D., Label-free quantitative proteomic analysis of tolerance to drought in Pisum sativum. Proteomics 2016, 16, 2776-2787.

39. Zybailov, B.; Mosley, A. L.; Sardiu, M. E.; Coleman, M. K.; Florens, L.; Washburn, M. P., Statistical analysis of membrane proteome expression changes in Saccharomyces cerevisiae. J Proteome Res 2006, 5, 2339-2347.

40. Kaiser, H. M., An index of factorial simplicity. Psychometrika 1974, 39, 31-32.

41. Bartlett, M. S., Properties of sufficiency and statistical tests. $P$ R Soc London, Series A 160, 1937: 268-282.

42. Suo, J.; Zhao, Q.; Zhang, Z.; Chen, S.; Cao, J.; Liu, G.; Wei, X.; Wang, T.; Yang, C.; Dai, S., Cytological and Proteomic Analyses of Osmunda cinnamomea Germinating Spores Reveal Characteristics of Fern Spore Germination and Rhizoid Tip Growth. Mol Cell Proteomics 2015, 14, 2510-2534.

43. MacLean, B.; Tomazela, D. M.; Shulman, N.; Chambers, M.; Finney, G. L.; Frewen, B.; Kern, R.; Tabb, D. L.; Liebler, D. C.; MacCoss, M. J., Skyline: an open source document editor for creating and analyzing targeted proteomics experiments. Bioinformatics 2010, 26, 966-968.

44. Chang, C. Y.; Picotti, P.; Huttenhain, R.; Heinzelmann-Schwarz, V.; Jovanovic, M.; Aebersold, R.; Vitek, O., Protein significance analysis in selected reaction monitoring (SRM) measurements. Mol Cell Proteomics 2012, 11, M111 014662.

45. Cox, J.; Mann, M., MaxQuant enables high peptide identification rates, individualized p.p.b.-range mass accuracies and proteome-wide protein quantification. Nat Biotechnol 2008, 26, (12), 1367-72.

46. Vizcaino, J. A.; Csordas, A.; Del-Toro, N.; Dianes, J. A.; Griss, J.; Lavidas, I.; Mayer, G.; Perez-Riverol, Y.; Reisinger, F.; Ternent, T.; Xu, Q. W.; Wang, R.; 
Hermjakob, H., 2016 update of the PRIDE database and its related tools. Nucleic Acids Res 2016, 44, 11033.

47. Boller, T., Roles of proteolytic enzymes in interaction of plant and other organisms. In In Plant Proteolytic Enzymes, Dalling, M. J., Ed. Boca Raton, FL: CRC Press: 1986; pp 67-96.

48. Carrillo, E.; Rubiales, D.; Castillejo, M. A., Proteomic Analysis of Pea (Pisum sativum L.) Response During Compatible and Incompatible Interactions with the Pea Aphid (Acyrthosiphon pisum H.). Plant Mol Biol Rep 2014, 32, 697-718.

49. Castillejo, M. A.; Amiour, N.; Dumas-Gaudot, E.; Rubiales, D.; Jorrín, J. V., A proteome approach to studying plant response to crenate broomrape (Orobanche crenata) in pea (Pisum sativum). Phytochemistry 2004, 65, 1817 - 1828.

50. Castillejo, M. A.; Maldonado, A. M.; Dumas-Gaudot, E.; Fernández-Aparicio, M.; Susín, R.; Rubiales, D.; Jorrín, J., Differential expression proteomics to investigate responses and resistance to Orobanche crenata in Medicago truncatula. BMC Genomics 2009, 10, 294.

51. Castillejo, M. A.; Fernández-Aparicio, M.; Rubiales, D., Proteomic analysis by two-dimensional differential in gel electrophoresis (2D DIGE) of the early response of Pisum sativum to Orobanche crenata. J Exp Bot 2012, 63, 107-19.

52. Castillejo, M. A.; Curto, M.; Fondevilla, S.; Rubiales, D.; Jorrínn, J. V., TwoDimensional electrophoresis based proteomic analysis of the pea (Pisum sativum) in response to Mycosphaerella pinodes. J Agric Food Chem 2010, 58, 1282212832.

53. Coram, T. E.; Pang, E. C. K., Transcriptional profiling of chickpea genes differentially regulated by salicylic acid, methyl jasmonate and aminocyclopropane carboxylic acid to reveal pathways of defense related gene regulation. Funct Plant Biol 2007, 34, 52-64.

54. Pelloux, J.; Rusterucci, C.; Mellerowicz, E. J., New insights into pectin methylesterase structure and function. Trends Plant Sci 2007, 12, 267-77.

55. Marty, P.; Jouan, B.; Bertheau, Y.; Vian, B.; Goldberg, R., Charge density in stem cell walls of Solanum tuberosum genotypes and susceptibility to blackleg. Phytochemistry 1997, 44, 1435-1441.

56. Schmohl, N.; Pilling, J.; Fisahn, J.; Horst, W., Pectin methylesterase modulates aluminium sensitivity in Zea mays and Solanum tuberosum. Physiol Plant 2000, 109, 419-427.

57. Dorokhov, Y. L.; Frolova, O. Y.; Skurat, E. V.; Ivanov, P. A.; Gasanova, T. V.; Sheveleva, A. A.; Ravin, N. V.; Makinen, K. M.; Klimyuk, V. I.; Skryabin, K. G.; Gleba, Y. Y.; Atabekov, J. G., A novel function for a ubiquitous plant enzyme pectin methylesterase: the enhancer of RNA silencing. FEBS Lett 2006, 580, 3872-8.

58. Clulow, S. A.; Lewis, B. G.; Matthews, P., Expression of resistance to Mycosphaerella pinodes in Pisum sativum. Plant Pathol 1992, 41, 362-369.

59. Grant, M.; Mansfield, J., Early events in host-pathogen interactions. Curr Opin Plant Biol 1999, 2, 312-319.

60. Mittler, R., Oxidative stress, antioxidants and stress tolerance. TRENDS Plant Sci 2002, 7, 405-410.

61. Ferl, R., 14-3-3 proteins and signal transduction. Annu Rev Plant Physiol Plant Mol Biol 1996, 47, 49-73.

62. Yan, J.; He, C.; Wang, J.; Mao, Z.; Holaday, S. A.; Allen, R. D.; Zhang, H., Overexpression of the Arabidopsis 14-3-3 Protein GF14 $\lambda$ in Cotton Leads to a 
"Stay-Green" Phenotype and Improves Stress Tolerance under Moderate Drought Conditions. Plant Cell Physiol 2004, 45, 1007-1014.

63. Castillejo, M. A.; Bani, M.; Rubiales, D., Understanding pea resistance mechanisms in response to Fusarium oxysporum through proteomic analysis. Phytochemistry 2015, 115, 44-58.

64. Kozuleva, M.; Goss, T.; Twachtmann, M.; Rudi, K.; Trapka, J.; Selinski, J.; Ivanov, B.; Garapati, P.; Steinhoff, H. J.; Hase, T.; Scheibe, R.; Klare, J. P.; Hanke, G. T., Ferredoxin:NADP $(\mathrm{H})$ Oxidoreductase Abundance and Location Influences Redox Poise and Stress Tolerance. Plant Physiol 2016, 172, 14801493.

65. Wang, M.; Jia, Y.; Xu, Z.; Xia, Z., Impairment of Sulfite Reductase Decreases Oxidative Stress Tolerance in Arabidopsis thaliana. Front Plant Sci 2016, 7, 1843.

66. Hell, R., Molecular physiology of plant sulfur metabolism. Planta 1997, 202, 138-148.

67. Alscher, R. G., Biosynthesis and antioxidant function of glutathione in plants. Physiol Plant 1989, 77, 457-464.

68. Noctor, G.; Arisi, A. M.; Jouanin, L.; Kunert, K. J.; Rennenberg, H.; Foyer, C. H., Glutathione: biosynthesis, metabolism and relationship to stress tolerance explored in transformed plants. J Exp Bot 1998, 49, 623-647.

69. Yarmolinsky, D.; Brychkova, G.; Kurmanbayeva, A.; Bekturova, A.; Ventura, Y.; Khozin-Goldberg, I.; Eppel, A.; Fluhr, R.; Sagi, M., Impairment in Sulfite Reductase Leads to Early Leaf Senescence in Tomato Plants. Plant Physiol 2014, 165, 1505-1520.

70. Marrs, K. A., The functions and regulation of glutathione S-transferases in plants. Ann Rev Plant Physil Plant Mol Biol 1996, 47, 127-158.

71. Yoshioka, H.; Shiraishi, T.; Nasu, K.; Yamada, T.; Ichinose, Y.; Oku, H., Suppression of activation of chitinase and B-1,3-glucanase in pea epicotyls by orthovanadate and suppressor from Mycosphaerella pinodes. Ann Phytopathol Soc Japan 1992, 58, 405-410.

72. Kiba, A.; Miyake, C.; Toyoda, K.; Ichinose, Y.; Yamada, T.; Shiraishi, T., Superoxide generation in extracts from isolated plant cell walls is regulated by fungal signal molecules. Phytopathology 1997, 87, 846-852. 
Table 1. List of peptides markers selected based on multivariate factor analysis

\begin{tabular}{|c|c|c|c|c|c|c|c|}
\hline \multirow[b]{2}{*}{ Protein ID } & \multirow[b]{2}{*}{ Peptides Sequences } & \multirow[b]{2}{*}{ Precursor $\mathbf{m} / \mathbf{z}$} & \multirow[b]{2}{*}{ Protein Function } & \multirow[b]{2}{*}{ Protein Description } & \multicolumn{3}{|c|}{ Factor $^{*}$} \\
\hline & & & & & 1 & 2 & 3 \\
\hline G7IAA3 & NLANPTALLLSSVSMLR & 900.5060 & Carbohydrate metabolism & Isocitrate dehydrogenase (NAD+) & $\underline{0,77}$ & $-0,39$ & $-0,03$ \\
\hline O24298 & FTVTQLIQGNVWLK & 823.9669 & Cellular processes & Pectinesterase & 0,02 & $\underline{0,78}$ & $-0,11$ \\
\hline O24298 & TVAEAVASAPDNGK & 665.3359 & Cellular processes & Pectinesterase & $-0,25$ & $\underline{0,86}$ & $-0,13$ \\
\hline O24298 & VGADQSVINR & 529.7831 & Cellular processes & Pectinesterase & $-0,11$ & $\underline{0,88}$ & $-0,02$ \\
\hline O24298 & IDAFQDTLYAHSNR & 550.9339 & Cellular processes & Pectinesterase & $-0,08$ & $\underline{0,90}$ & $-0,03$ \\
\hline Q0KKQ5 & DILEIDHPEGPFGTK & 834.4174 & Energy metabolism & Cytochrome c oxidase subunit $\mathrm{Vb}$ & $\underline{-0,75}$ & 0,18 & $-0,20$ \\
\hline contig2217 & FQGQATDVNLAR & 660.3388 & Folding, sorting and degradation & $\begin{array}{l}\text { ATP-dependent Clp protease } \\
\text { proteolytic subunit-related protein } 4\end{array}$ & $\underline{-0,71}$ & 0,57 & 0,05 \\
\hline contig2217 & TELVNLLAK & 500.8055 & Folding, sorting and degradation & $\begin{array}{l}\text { ATP-dependent Clp protease } \\
\text { proteolytic subunit-related protein } 4\end{array}$ & $\underline{-0,70}$ & 0,34 & 0,30 \\
\hline contig20430 & AMEVDEKPTEDYNDIGGLEK & 1127.0150 & Folding, sorting and degradation & $\begin{array}{l}26 \mathrm{~S} \text { protease regulatory subunit } 6 \mathrm{~A} \\
\text { homolog }\end{array}$ & $\underline{0,77}$ & $-0,39$ & 0,22 \\
\hline contig20430 & DATEVNHEDFNEGIIQVQAK & 753.0292 & Folding, sorting and degradation & $\begin{array}{l}26 \mathrm{~S} \text { protease regulatory subunit } 6 \mathrm{~A} \\
\text { homolog }\end{array}$ & $\underline{-0,78}$ & 0,33 & $-0,04$ \\
\hline contig20430 & LAGPQLVQMFIGDGAK & 822.9425 & Folding, sorting and degradation & $\begin{array}{l}26 \mathrm{~S} \text { protease regulatory subunit } 6 \mathrm{~A} \\
\text { homolog }\end{array}$ & $\underline{0,74}$ & $-0,34$ & $-0,04$ \\
\hline
\end{tabular}




\begin{tabular}{|c|c|c|c|c|c|c|c|}
\hline contig4092 & VEIAHIAELIELPIDHVER & 732.7389 & Folding, sorting and degradation & $\begin{array}{l}26 \mathrm{~S} \text { proteasome non-ATPase } \\
\text { regulatory subunit } 11\end{array}$ & $\underline{0,84}$ & $-0,02$ & 0,06 \\
\hline contig4092 & VLDDPSSSPEALR & 693.3490 & Folding, sorting and degradation & $\begin{array}{l}26 \mathrm{~S} \text { proteasome non-ATPase } \\
\text { regulatory subunit } 11\end{array}$ & $\underline{-0,72}$ & 0,18 & $-0,16$ \\
\hline contig3912 & SGVADMVNTGGR & 582.2773 & Folding, sorting and degradation & Leucine aminopeptidase 2 & $\underline{0,84}$ & $-0,23$ & $-0,04$ \\
\hline Q75NZ0 & VSNQLYLTMDDLADQFGIGTLR & 824.0809 & Redox & Sulfite reductase [ferredoxin] & $\underline{0,74}$ & $-0,06$ & 0,00 \\
\hline P59220 & DTDSEEELKEAFR & 784.8574 & Signalling & Calmodulin-7 & 0,20 & $-0,19$ & $\underline{0,91}$ \\
\hline P59220 & EADVDGDGQINYEEFVK & 964.4314 & Signalling & Calmodulin-7 & 0,09 & $-0,25$ & $\underline{0,92}$ \\
\hline P59220 & VFDKDQNGFISAAELR & 905.4601 & Signalling & Calmodulin-7 & 0,04 & 0,01 & $\underline{0,96}$ \\
\hline contig04805 & TLTAVHEAMLEDVVLPAEIVGK & 779.0908 & Translation & 40S ribosomal protein $\mathrm{S} 7-2$ & $\underline{0,74}$ & $-0,54$ & 0,18 \\
\hline contig2390 & KELDAEVHR & 548.7909 & Translation & 60S ribosomal protein L5 & $-0,06$ & $\underline{0,74}$ & $-0,30$ \\
\hline contig03572 & KFIPEMIGK & 531.8044 & Translation & 40S ribosomal protein $\mathrm{S} 3 \mathrm{a}$ & 0,13 & 0,12 & $\underline{-0,72}$ \\
\hline contig04086 & WYEIASFPSFFQPK & 873.9299 & Transport & Outer membrane lipoprotein blc & $\underline{-0,77}$ & 0,15 & $-0,27$ \\
\hline O24303 & DDTEYIYLNQLGGILGLTGK & 1092.0652 & Transport & Protein TIC110 & $\underline{0,96}$ & 0,04 & 0,12 \\
\hline contig21564 & MMMTSGEAVK & 542.7454 & Transport & ADP, ATP carrier protein 1 & $\underline{0,78}$ & $-0,29$ & 0,06 \\
\hline
\end{tabular}

${ }^{*}$ Principal Axis Factoring. Rotation Method: Varimax with Kaiser Normalization. The 3 first factors of the 14 extracted are showed. Unrotated factors loadings are the correlations between the variable and the factor. Loadings equal or greater than an absolute value of 0.7 are underlined. 
A) Inoculation assay

Susceptible

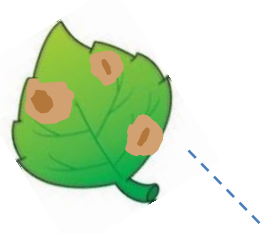

Resistant

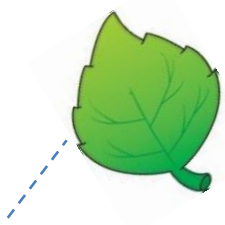

\section{Protein extraction}

B) Shotgun proteomic analysis (LC-MSMS) for protein identification

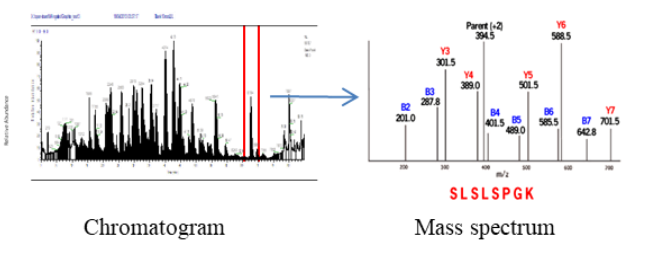

C) Statistical analysis: target peptide list
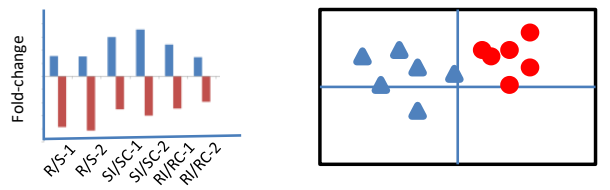

Target peptides

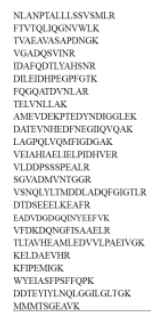

D) Quantitative analysis of the target peptides in a segregating population $F_{10}$

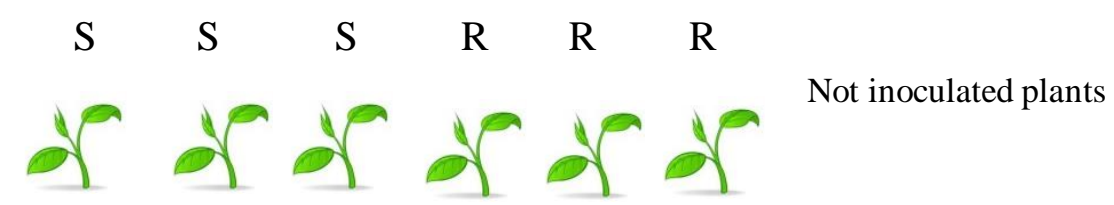

Targeted proteomics: MS1 + DIA analysis

E) Peptides markers selection in the segregating population based on statistical analysis

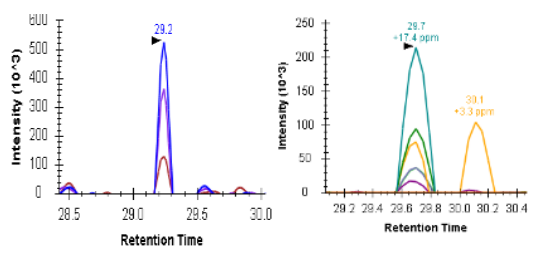


Figure 2

A)

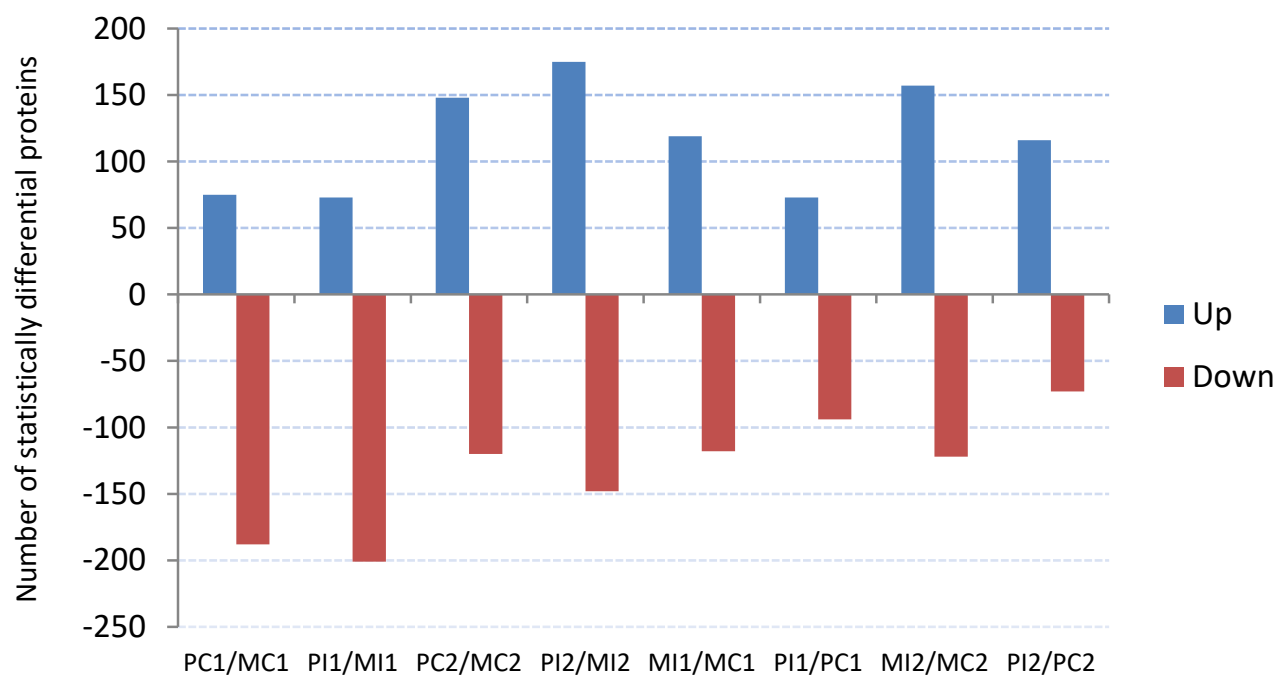

B)

C)
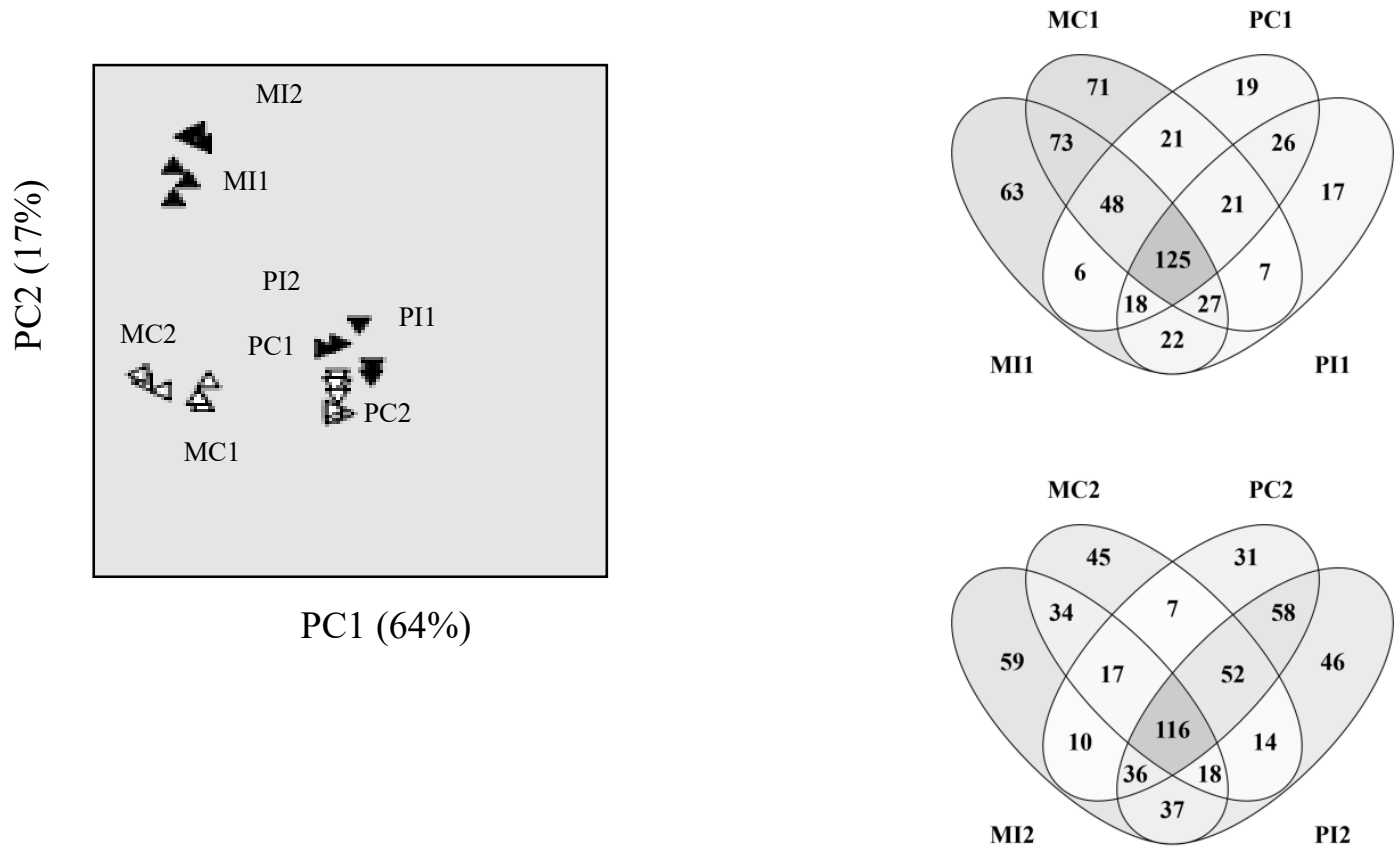
Figure 3

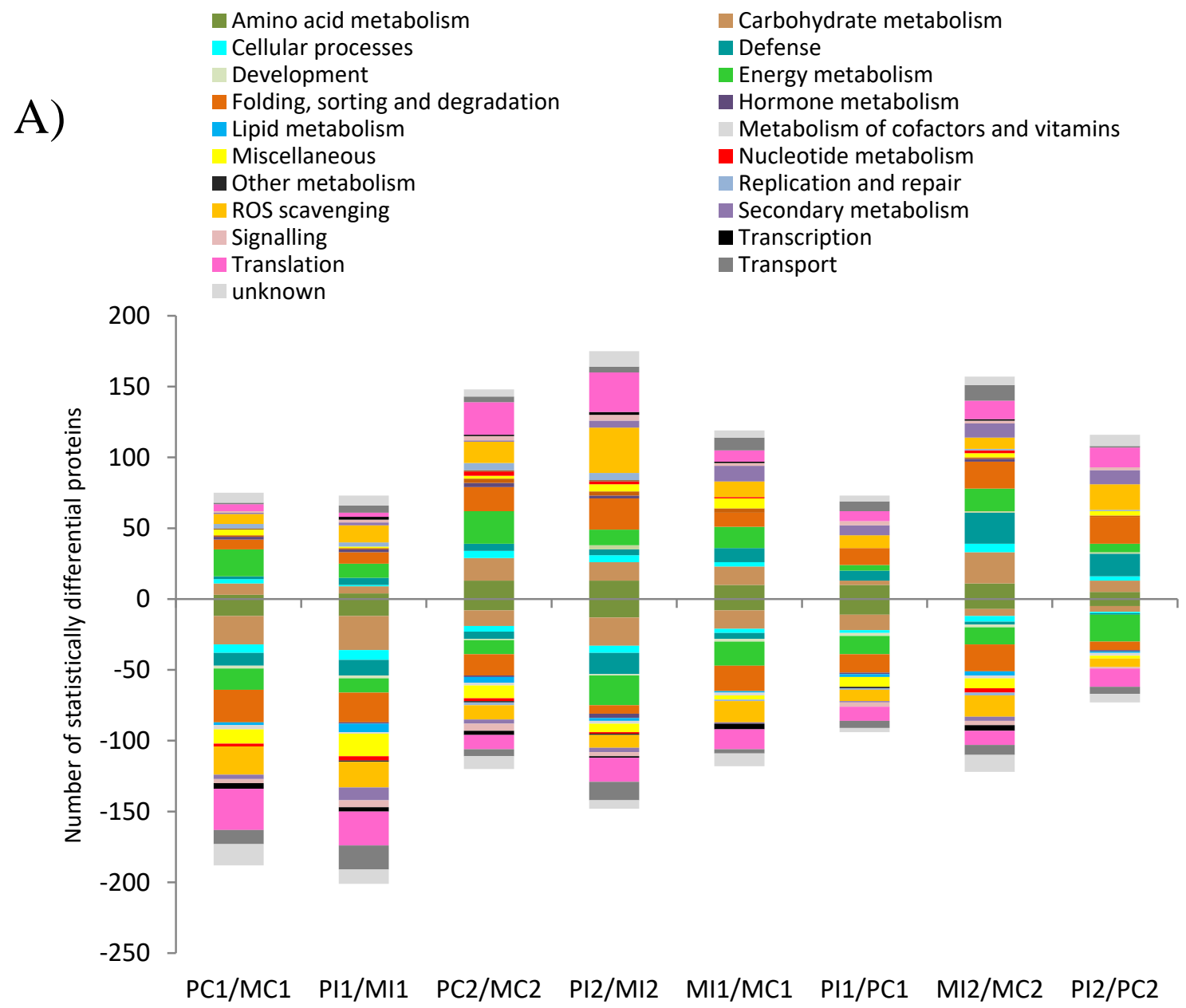

B)

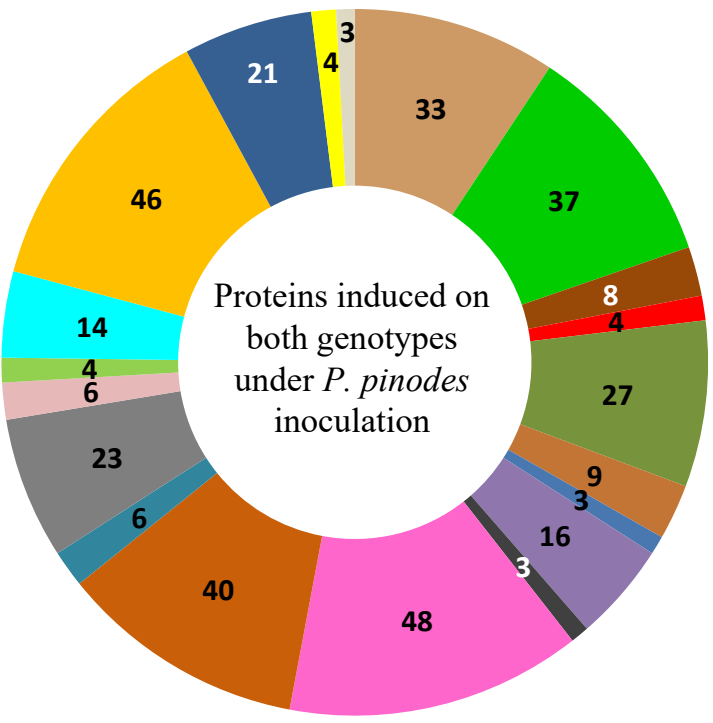

C)

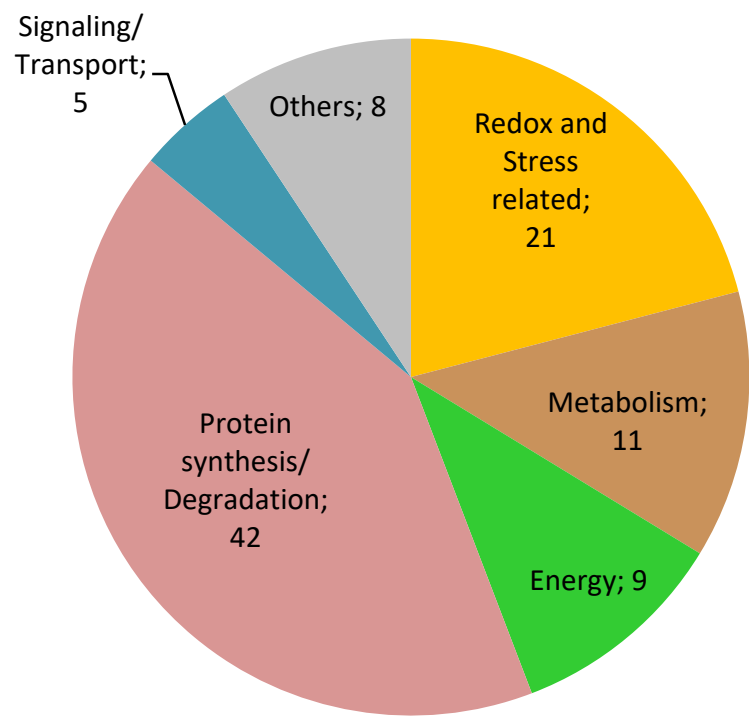


Figure 4

\begin{tabular}{|c|c|c|c|c|c|}
\hline PI1/MI1 & & & PI2/MI2 & & \\
\hline $1^{\circ}$ & 13 & 25 & $1^{\circ}$ & 13 " & $25=$ \\
\hline $2{ }^{\circ}$ & $14 \square$ & $26=$ & $2{ }^{\circ}$ & $14=$ & 26 표 \\
\hline $3{ }^{\circ}$ & 15 & $27=$ & $3{ }^{\circ}$ & 15 . & $27=$ \\
\hline 4 & $16=$ & 28 & $4=$ & 16 ㅍ & 28 \\
\hline $5^{\circ}$ & 17 " & $29 \quad \because: \vdots$ & $5^{\circ}$ & 17 " & 29 स्मान्म \\
\hline $6^{\circ}$ & 18 . & $30 \pi$ & $6^{\circ}$ & 18 . & $30=$ \\
\hline $7{ }^{\square}$ & $19=$ & $31=$ & $7=$ & 19 ㅁ & 31 \\
\hline $8=$ & $20=$ & 32 & $8=$ & $20=$ & 32 \\
\hline 9 & 21. & 33 & 9 F & 21 & $33=$ \\
\hline $10=$ & 22 & $34:$ & 10 & $22{ }^{\circ}$ & $34:$ \\
\hline $11{ }^{\circ}$ & $23{ }^{\circ}$ & $35:$ & $11{ }^{\circ}$ & $23{ }^{\circ}$ & 35 I \\
\hline 12 . & 24 日 & 36 . & $12{ }^{\circ}$ & $24=$ & 36 . \\
\hline PI1/PC1 & & & PI2/PC2 & & \\
\hline $1^{\circ}$ & 13 & 25 & $1^{\circ}$ & 13 ㅁ. & 25 " \\
\hline $2{ }^{\circ}$ & 14 & 26. & $2{ }^{\circ}$ & 14 = & $26=$ \\
\hline $3{ }^{\circ}$ & 15 。 & $27=$ & $3{ }^{\circ}$ & $15{ }^{\circ}$ & $27=$ \\
\hline 4 & 16. & 28. & 4 & 16 = & 28 \\
\hline $5^{\circ}$ & 17 " & $29 \mathrm{in}$ & $5^{\circ}$ & 17 & 29 파표 \\
\hline $6^{\circ}$ & $188^{\circ}$ & $30 \mathrm{~F}$ & $6^{\circ}$ & 18 & $30=$ \\
\hline 7 & 19 ㅁ. & 31 & $7=$ & $19 \square$ & 31 \\
\hline 8 日 & $20=$ & 32 & 8 : & 20 & $32{ }^{\circ}$ \\
\hline 9 & $21:$ & $33=$ & 9 & $21:$ & $33=$ \\
\hline 10 & $22^{\circ}$ & $34:$ & 10 & 22 & 34 日 \\
\hline $11{ }^{\circ}$ & $233^{\circ}$ & $35:$ & $11{ }^{\circ}$ & $233^{\circ}$ & 35 : \\
\hline 12 . & 24 日 & 36 . & $12{ }^{\circ}$ & $24=$ & 36 . \\
\hline
\end{tabular}

1 lightreaction

2 major $\mathrm{CHO}$ metabolism 3 minor $\mathrm{CHO}$ metabolism

4 glycolysis

5 fermentation

6 glyoxylate cycle

7 oxidative pentose phosphate

$8 \mathrm{TCA} /$ org transformation

9 mitochondrial e transport

10 cell wall

11 lipid metabolism

$12 \mathrm{~N}$-metabolism

13 amino acid metabolism

14 S-assimilation

15 metal handling

16 secondary metabolism

17 hormon metabolism

18 Co-factor and vitamine metabolism

19 tetrapyrrole synthesis

20 stress

21 redox

22 polyamine metabolism

23 nucleotide metabolism

24 biodegradation of xenobiotics

25 C1-metabolism

26 miscellaneous

27 RNA regulation

28 DNA

29 protein regulation

30 signaling

31 cell organization

32 micro RNA

33 development

34 transport

35 unknown 
Figure 5

A)

FQGQATDVNLAR, Charge 2

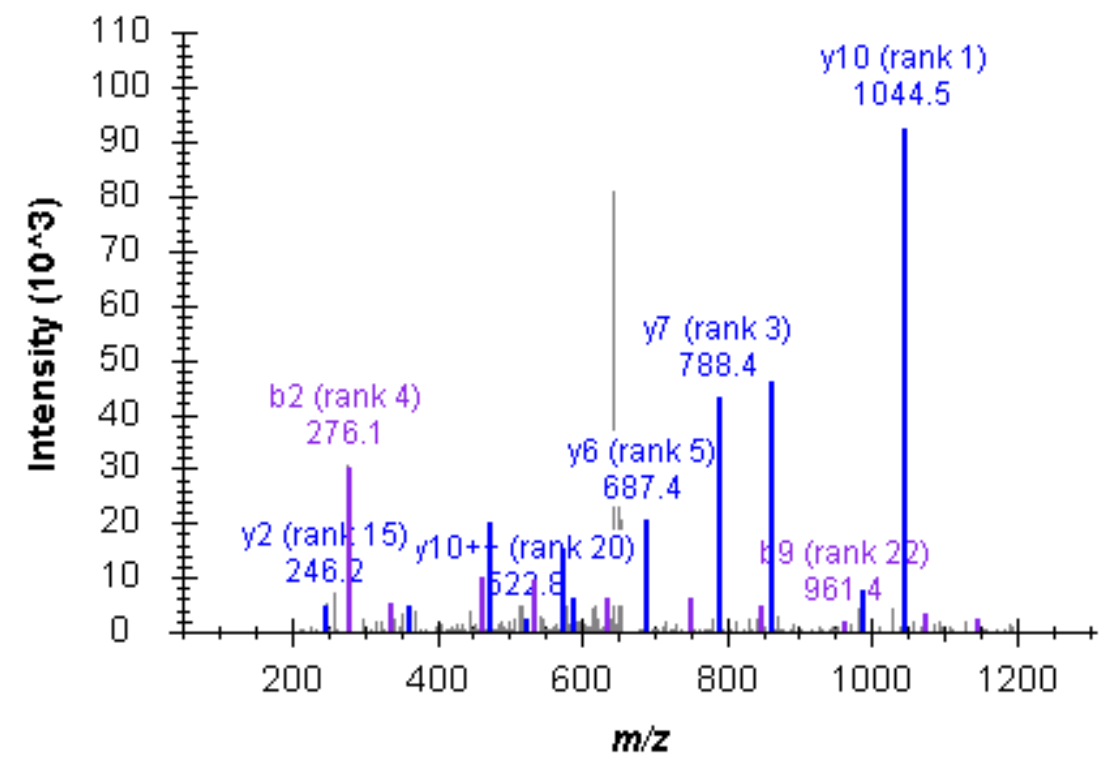

B)

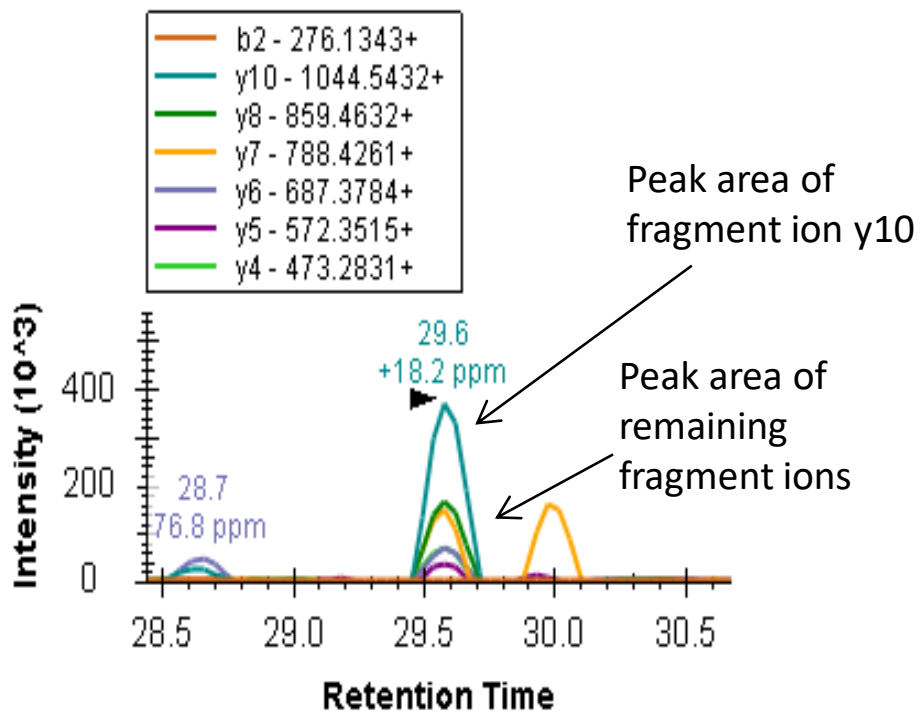




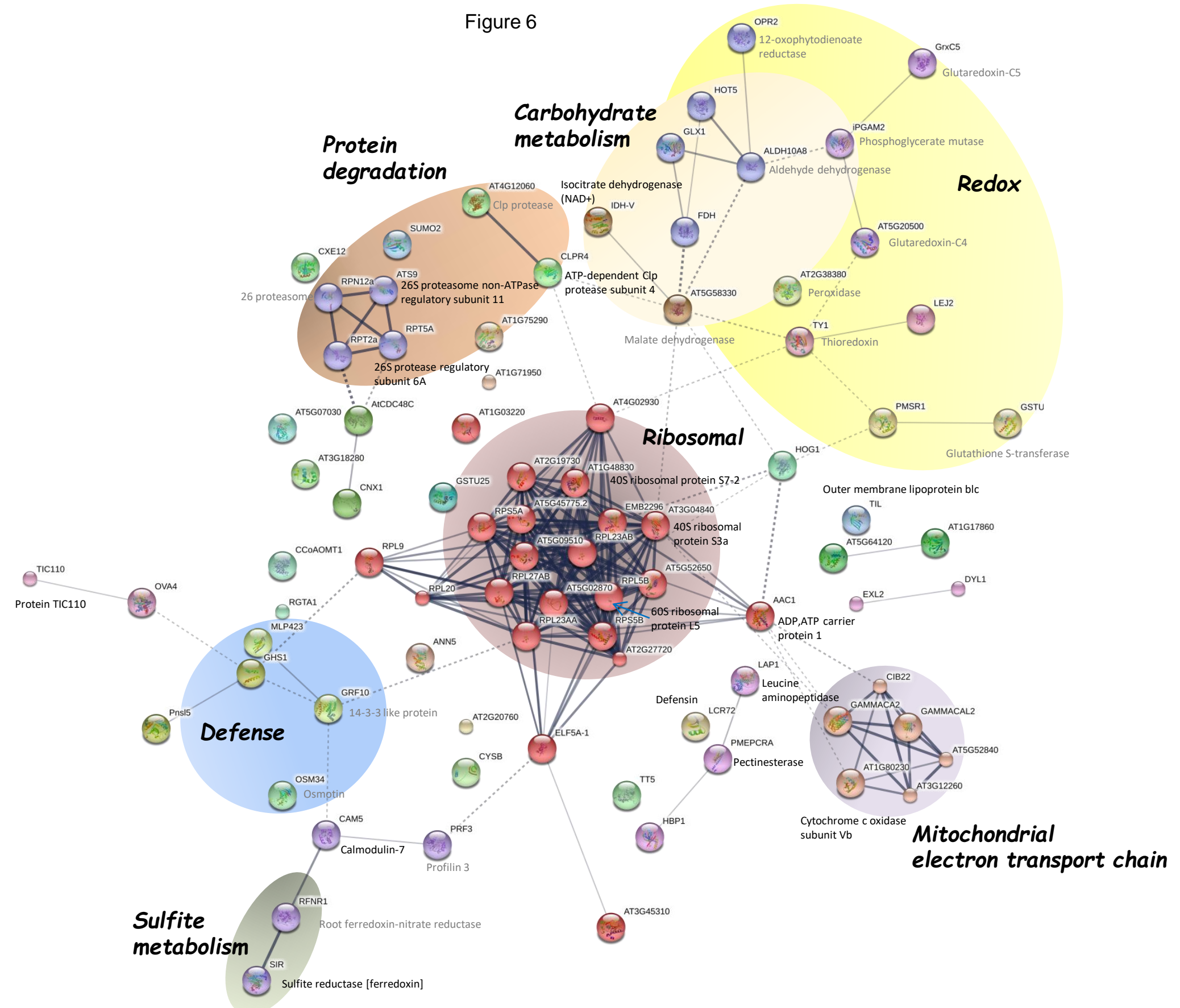

